\title{
Efficacy on anaplastic thyroid carcinoma of valproic acid alone or in combination with doxorubicin, a synthetic chenodeoxycholic acid derivative, or lactacystin
}

\author{
TAE HYUN KIM ${ }^{1}$, YOUNG HYUN YOO ${ }^{1}$, DO-YOUNG KANG ${ }^{2}$, HONGSUK SUH ${ }^{4}$, \\ MOON KI PARK ${ }^{5}$, KI-JAE PARK ${ }^{3}$ and SUNG-HEUN KIM ${ }^{3}$
}

\begin{abstract}
Departments of ${ }^{1}$ Anatomy and Cell Biology, ${ }^{2}$ Nuclear Medicine and ${ }^{3}$ Surgery, Dong-A University College of Medicine, Busan 602-714; ${ }^{4}$ Department of Chemistry, Pusan National University College of Natural Science, Busan 609-735;

${ }^{5}$ Department of Herbal Pharmaceutical Engineering, Daegu Haany University, Gyeongsangbuk-do 712-715, Korea
\end{abstract}

Received November 11, 2008; Accepted January 19, 2009

DOI: 10.3892/ijo_00000262

\begin{abstract}
The present study investigated the mechanism underlying the antitumor activity of the histone deacetylases inhibitor valproic acid (VPA), alone and in combination with doxorubicin, a synthetic chenodeoxycholic acid derivative (HS-1200), or the proteasome inhibitor lactacystin on cultured anaplastic thyroid carcinoma KAT-18 cells. Cell viability was evaluated by trypan-blue exclusion. Western blotting determined caspase and histone deacetylase activities and expression of poly(ADP)-ribose polymerase. Induction of apoptosis was identified by Hoechst staining, DNA electrophoresis, DNA hypoploidy and cell cycle phase analysis, and measurement of mitochondrial membrane potential. Subcellular translocation of apoptosis inducing factor and caspase-activated DNase after treatment was determined by confocal microscopy following immunofluorescent staining. VPA treatment increased apoptotic death of KAT-18 cells. VPA treatment was also associated with degradation of procaspase-3, procaspase-7, and poly(ADP)ribose polymerase; induction of histone hyperacetylation; condensation of peripheral chromatin; decreased mitochondrial membrane potential and DNA content; and decreased translocation of apoptosis inducing factor and caspase-activated DNase. VPA in combination with doxorubicin, HS-1200, or lactacystin, applied at the highest concentrations that did not induce KAT-18 cell death, efficiently induced apoptosis in KAT-18 cells. The results suggest VPA combination therapy may represent an alternative therapeutic strategy for anaplastic thyroid carcinoma.
\end{abstract}

Correspondence to: Dr Sung-Heun Kim, Department of Surgery, Dong-A University College of Medicine, 3-1 Dongdaesin Dong, Seo Gu, Busan 602-714, Korea

E-mail: ksheun@dau.ac.kr

Key words: valproic acid, apoptosis, anaplastic thyroid cancer, doxorubicin, HS-1200, lactacystin

\section{Introduction}

One of the most important mechanisms in chromatin remodeling is acetylation-mediated posttranslational modification of the amino-terminal tails. Histone acetylation contributes to a 'histone code' that determines the activity of target genes (1). Histone deacetylases (HDACs) reciprocally regulate acetylation of core nucleosomal histones. HDACs catalyze the removal of acetyl groups on the aminoterminal lysine residues of core nucleosomal histones, and this activity is generally associated with transcriptional repression. Transcriptionally silent chromatin is composed of nucleosomes, histones that have low levels of acetylation at amino-terminal lysine residues. Acetylation of histones by neutralization of the positive charge contributed by lysine residues and by disruption of the nucleosome structure allows unfolding of the associated DNA and subsequent access by transcription factors. Changes in gene expression follow. Transcription factors such as Mad-1, bcl-6, and ETO also assemble HDACdependent transcriptional repressor complexes (2). Since aberrant recruitment of HDAC activity is associated with the development of certain human malignancies (3), HDAC is one therapeutic target for cancer treatment.

HDAC inhibitors (HDACIs) inhibit malignant cell growth in vitro and in vivo to bring about the reversion of oncogenetransformed cell morphology (4) and to induce apoptosis (5). Several classes of HDACIs have been identified; these include organic hydroxamic acids such as trichostatin A (TSA) and suberoyl anilide bishydroxamine (SAHA), short-chain fatty acids such as butyrates and valproic acid (VPA), cyclic tetrapeptides (e.g., trapoxin), and benzamides (e.g., MS-275) (6).

VPA is a well-known anticonvulsive agent that has been used in the treatment of epilepsy for almost 30 years. More recently, VPA has been shown to exhibit antineoplastic activity, inhibiting proliferation and inducing differentiation of primitive neuroectodermal tumor cells in vivo (7). VPA's antitumor activity is associated with the targeting of HDAC $(8,9)$. In particular, VPA down-regulates class II HDAC protein levels significantly in several cell types, in contrast to TSA, implying that VPA might be a more selective HDACI than TSA (10). 
To date, several studies have investigated the efficacy of VPA alone and as part of combination therapy for the treatment of various types of malignancy $(11,12)$. The present study extends this avenue of research by examining the mechanism underlying antitumor activity of VPA for anaplastic thyroid carcinoma (ATC) and to utilize the compound in novel combination treatments.

\section{Materials and methods}

Reagents. Rabbit polyclonal anti-caspase-3, caspase-7, caspaseactivated DNase (CAD) and apoptosis inducing factor (AIF) antibodies were obtained from Santa Cruz Biotechnology (Santa Cruz, CA, USA). Mouse polyclonal anti-human poly(ADP)-ribose polymerase (PARP) antibody was from Oncogene (Cambridge, MA, USA); fluorescein isothiocynate (FITC)-conjugated goat anti-rabbit and horse anti-mouse immunoglobulins (IgGs) were purchased from Vector Laboratories (Burlingame, CA, USA). Rabbit polyclonal anti-human histone H4 antibody was from Cell Signaling Technology (Beverly, MA, USA). Horseradish peroxidase (HRP)-conjugated donkey anti-rabbit and sheep anti-mouse IgGs were from Amersham Pharmacia Biotech (Piscataway, NJ, USA). VPA, dimethyl sulfoxide (DMSO), Hoechst 33342 , RNase A, proteinase K, aprotinin, leupeptin, phenylmethylsulfonyl fluoride (PMSF), phenol red-free RPMI-1640, and propidium iodide were obtained from Sigma-Aldrich (St. Louis, MO, USA). Fetal bovine seum (FBS), sodium pyruvate solution, and non-essential amino acid solution for minimum essential medium (MEM) were purchased from Gibco (Gaithersburg, MD, USA). Doxorubicin was obtained from Dong-A Pharmaceutical (Seoul, Korea). The proteasome inhibitor lactacystin was acquired from Calbiochem (San Diego, CA, USA). The synthetic chenodeoxycholic acid (CDCA) derivative HS-1200, which is a conjugated form of CDCA with $\beta$-alanine benzyl ester $(N-[(3 \alpha, 5 \beta, 7 \alpha)-3,7$ dihydroxy-24-oxocholan-24-yl] ß-alanine benzyl ester), was synthesized as previously described (13). 5,5',6,6'-tetrachloro1,1',3,3'-tetraethylbenzimidazol carbocyanine iodide (JC-1) was purchased from Molecular Probes (Eugene, OR, USA). SuperSignal West Pico enhanced chemiluminescence Western blot detection reagent was purchased from Thermo Scientific (Rockford, IL, USA).

Cell culture. Cells of the KAT-18 cell line (kindly provided by Dr Ain KB, University of Kentucky Chandler Medical Center, Lesington, KY, USA) were maintained at $37^{\circ} \mathrm{C}$ in an atmosphere of $5 \% \mathrm{CO}_{2}$ in RPMI-1640 with $2 \mathrm{mM} \mathrm{L-glutamine}$ and Earle's Balanced Salt Solutions adjusted to contain $2.0 \mathrm{~g} / 1$ sodium bicarbonate, $0.1 \mathrm{mM}$ non-essential amino acids, $1.0 \mathrm{mM}$ sodium pyruvate, and $10 \%$ FBS. The medium was replaced two to three times per week and cells were passaged at subconfluency.

VPA treatment and assessment of cell viability. Stock solutions of 2 M VPA made by dissolving the drug in phosphatebuffered saline (PBS) were kept at $-20^{\circ} \mathrm{C}$ until required. Twenty-four hours after KAT-18 cells were subcultured, the original medium was removed. Cells were washed with PBS and then incubated in fresh medium. A volume of the VPA stock solution was added to the medium to obtain a final concentration of $4.5 \mathrm{mM}$. After $0,8,16,24,48$, and $72 \mathrm{~h}$ cells were harvested, stained with trypan-blue, and counted using a hemacytometer to determine viability. Preliminary experiments (not shown) revealed that the DMSO concentration used had no effect on KAT-18 cell proliferation.

Assessment of co-treatment of VPA and doxorubicin, HS-1200, or lactacystin. Since $1 \mathrm{mM}$ VPA, $0.25 \mu \mathrm{M}$ doxorubicin, $25 \mu \mathrm{M}$ HS-1200, or $1 \mu \mathrm{M}$ lactacystin represented the highest concentrations that did not induce KAT-18 cell death (data not shown), we determined to utilize that particular concentration of each compound for the combination treatment study. KAT-18 cells were co-treated with $1 \mathrm{mM} \mathrm{VPA}$ and $0.25 \mu \mathrm{M}$ doxorubicin, $25 \mu \mathrm{M}$ HS-1200, or $1 \mu \mathrm{M}$ lactacystin for $48 \mathrm{~h}$. Cells were harvested and viability was determined as described above.

Hoechst staining. Cells were harvested and the cell suspension was cytocentrifuged onto a clean, fat-free glass slide. The samples were stained in $4 \mu \mathrm{g} / \mathrm{ml}$ Hoechst 33342 for $30 \mathrm{~min}$ at $37^{\circ} \mathrm{C}$ and fixed for $10 \mathrm{~min}$ in $4 \%$ paraformaldehyde.

DNA electrophoresis. Cells $\left(2 \times 10^{6}\right)$ were resuspended in $1.5 \mathrm{ml}$ of lysis buffer consisting of $10 \mathrm{mM}$ Tris ( $\mathrm{pH} 7.5), 10 \mathrm{mM}$ ethylene diamine tetraacetic acid (EDTA) (pH 8.0), $10 \mathrm{mM}$ $\mathrm{NaCl}$, and $0.5 \%$ sodium dodecyl sulfate into which $200 \mu \mathrm{g} / \mathrm{ml}$ proteinase $\mathrm{K}$ was added. After samples were incubated overnight at $48^{\circ} \mathrm{C}, 200 \mu \mathrm{l}$ of ice cold $5 \mathrm{M} \mathrm{NaCl}$ was added and the supernatant containing fragmented DNA was collected after centrifugation. The DNA was then precipitated overnight at $20^{\circ} \mathrm{C}$ in $50 \%$ isopropanol and treated with RNase A for $1 \mathrm{~h}$ at $37^{\circ} \mathrm{C}$. A $15-\mu 1$ volume of DNA from $10^{6}$ cells was loaded on each lane of $2 \%$ agarose gels in Tris-acetic acid/EDTA buffer containing $0.5 \mu \mathrm{g} / \mathrm{ml}$ ethidium bromide. The DNA fragments were separated by $1.8 \%$ agarose gel electrophoresis at $50 \mathrm{~mA}$ for $1.5 \mathrm{~h}$ and visualized under ultraviolet light.

Quantification of DNA hypoploidy and cell cycle phase analysis by flow cytometry. Ice-cold $95 \%$ ethanol with $0.5 \%$ Tween-20 was added into a cell suspension to produce $70 \%$ ethanol. Fixed cells were pelleted, and washed with PBS containing $1 \%$ bovine serum albumin (BSA) (PBS-BSA). Cells were resuspended in $1 \mathrm{ml}$ PBS containing 11 Kunitz $\mathrm{U} / \mathrm{ml} \mathrm{RNase}$, incubated at $4^{\circ} \mathrm{C}$ for $30 \mathrm{~min}$, washed once with PBS-BSA, and resuspended in $50 \mu \mathrm{g} / \mathrm{ml}$ propidium iodide. After cells had been incubated at $4^{\circ} \mathrm{C}$ for $30 \mathrm{~min}$ in the dark and washed with PBS, the DNA content was measured on an Epics XL (Beckman Coulter, Fullerton, CA, USA) and data were analyzed using the Multicycle software, which allowed a simultaneous estimation of cell cycle parameters and apoptosis.

Western blot analysis. Cells $\left(2 \times 10^{6}\right)$ treated with each drug were washed twice with ice-cold PBS and resuspended in $200 \mu \mathrm{l}$ ice-cold solubilizing buffer consisting of $300 \mathrm{mM}$ $\mathrm{NaCl}, 50 \mathrm{mM}$ Tris- $\mathrm{HCl}$ (pH 7.6), 0.5\% Triton X-100, 2 mM phenylmethylsulphonyl fluoride, $2 \mu \mathrm{l} / \mathrm{ml}$ aprotinin, and $2 \mu \mathrm{l} / \mathrm{ml}$ leupeptin. Following incubation at $4{ }^{\circ} \mathrm{C}$ for $30 \mathrm{~min}$, the cell lysate was centrifuged at $14,000 \mathrm{rpm}$ for $15 \mathrm{~min}$ at $4^{\circ} \mathrm{C}$. The protein concentration was determined using a commercial 
A

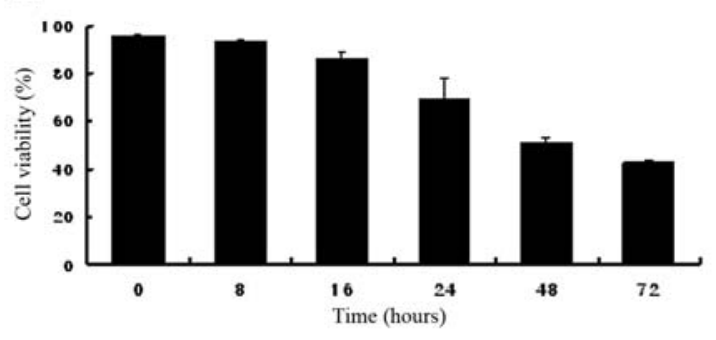

C
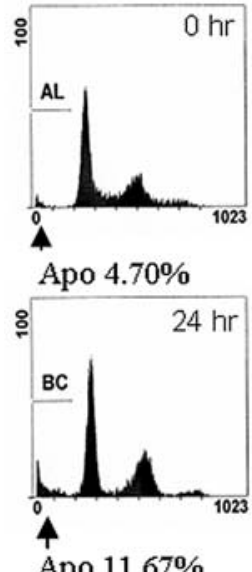

Apo $11.67 \%$

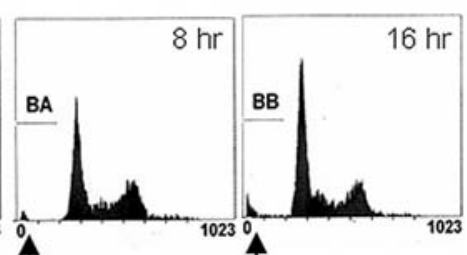

Apo $3.43 \%$
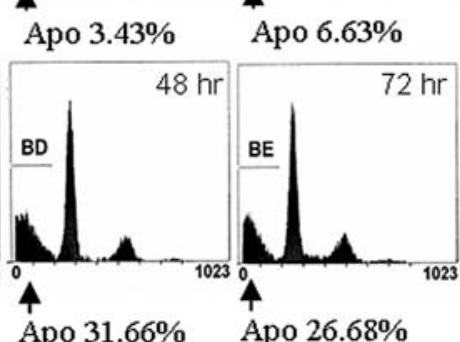

B
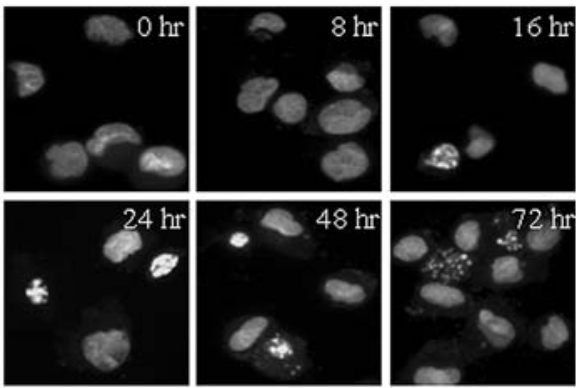

D

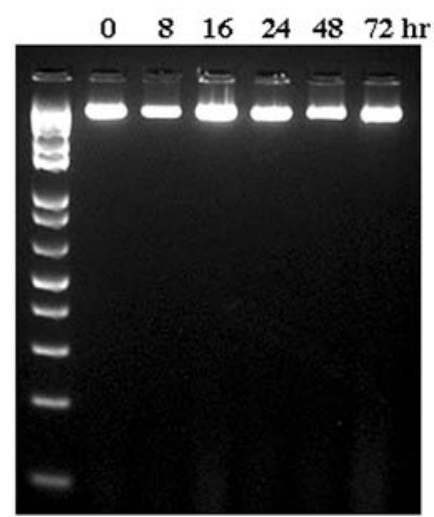

Figure 1. VPA induces apoptosis in KAT 18 cells. KAT-18 cells were incubated with 4.5 mM VPA for 0, 8, 16, 24, 48, and 72 h. (A) VPA efficiently reduced viability in KAT-18 cells. Here and in Figs. 3, 5, and 7, viability was determined by the trypan-blue dye exclusion assay, and four independent assays were performed with data representing the mean \pm SD.of the means obtained from triplicates of each experiment. (B) Quantification of apoptosis based on nuclear morphology. KAT-18 cells were collected at each time-point and assessed for apoptosis by Hoechst 33342 staining. (C) The kinetic analysis of the effect of $45 \mathrm{mM}$ VPA on KAT-18 cell cycle progression and induction of apoptosis. DNA content was measured using a FACScan flow cytometry system. The number below each photograph presents percentage of apoptotic cells. Data shown are representatives of four independent experiments. (D) DNA fragmentation analysis on the agarose gel electrophoresis. Ladder-like DNA fragments were not observed.

version of the Bradford protein assay (Bio-Rad, Richmond, CA, USA). Equivalent quantities of protein were loaded to a gel containing a $7.5-15 \%$ gradient of polyacrylamide for sodium dodecyl sulfate-polyacrylamide gel electrophoresis. The separated proteins were transferred to a nitrocellulose membrane (Amersham Pharmacia Biotech, Piscataway, NJ, USA) and reacted with anti-PARP, anti-caspase-3, anticaspase-7, and anti-histone $\mathrm{H} 4$ antibodies. Immunostaining with antibodies was performed using SuperSignal West Pico enhanced chemiluminescence substrate and detected with LAS-3000 Plus (Fuji Photo Film Co., Kanagawa, Japan). Equivalent protein loading was confirmed by Ponceau $\mathrm{S}$ staining.

Immunofluorescent staining. Cells were harvested and cytocentrifuged onto a clean, fat-free glass slide, fixed for $10 \mathrm{~min}$ in $4 \%$ paraformaldehyde, incubated with each primary antibody for $1 \mathrm{~h}$, washed three times each for 5 min with PBS, and then incubated with FITC-conjugated secondary antibody for $1 \mathrm{~h}$ at room temperature. Cells were then mounted with glycerol and examined using a Zeiss LSM 510 laser-scanning confocal microscope (Carl Zeiss, Göttingen, Germany).

Assay of mitochondrial membrane potential (MMP). JC-1 dye was added directly to the cell culture medium $(1 \mu \mathrm{M}$ final concentration) and incubated for $15 \mathrm{~min}$. The medium was then replaced with PBS. Flow cytometry to measure MMP was performed on an Epics XL (Beckman Coulter). Data were acquired and analyzed using EXPO32 ADC XL 4 color software. The analyzer threshold was adjusted on the forward scatter (FSC) channel to exclude noise and most of the subcellular debris.

Statistical analysis. The results of the experimental and control groups were tested for statistical significance by the non-parametric Kruskal-Wallis test. For in vitro experiments, four independent experiments were done. Statistical results are expressed as the mean and the standard deviation of the means obtained from triplicates of each independent experiment. In all cases, a $\mathrm{P}<0.05$ was considered significant.

\section{Results}

VPA reduces the viability of $K A T-18$ cells. Exposure of KAT-18 cells to $4.5 \mathrm{mM}$ VPA for $0,8,16,24,48$, and $72 \mathrm{~h}$ produced a significant decrease in cell viability in a timedependent manner, with cell death evident at 24, 48, and $72 \mathrm{~h}$ (Fig. 1A).

VPA-induced reduction of KAT-18 cell viability is caused by apoptosis. Microscopic observation of cells after Hoechst staining demonstrated condensation on peripheral chromatin 
A
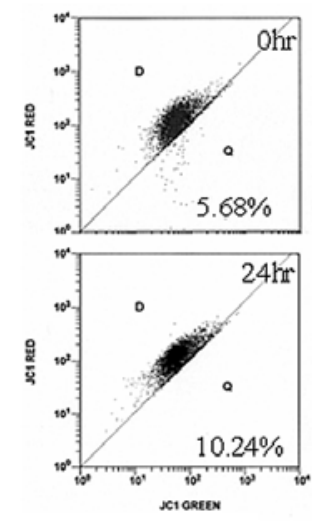
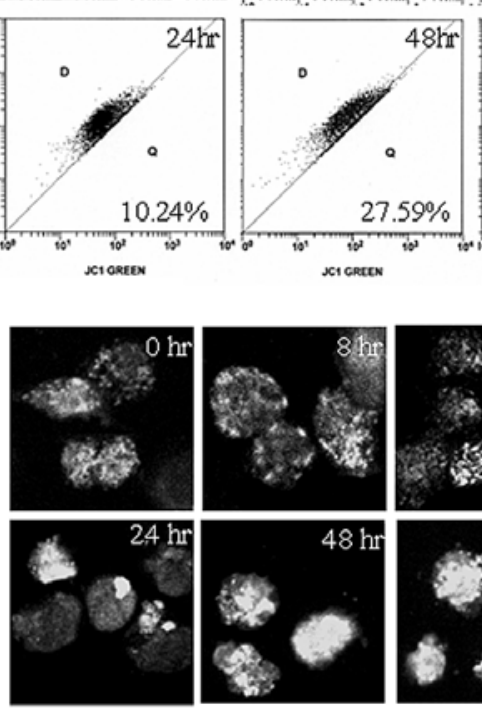

AIF
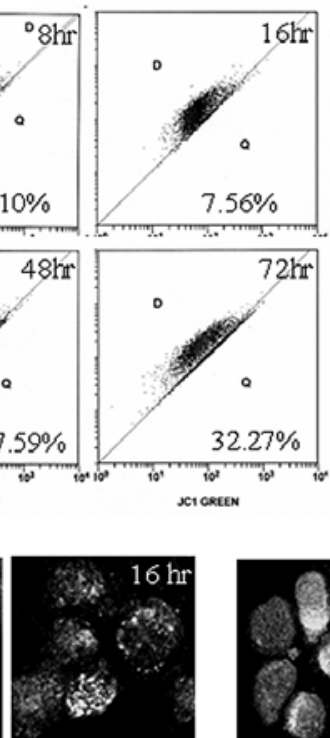

B
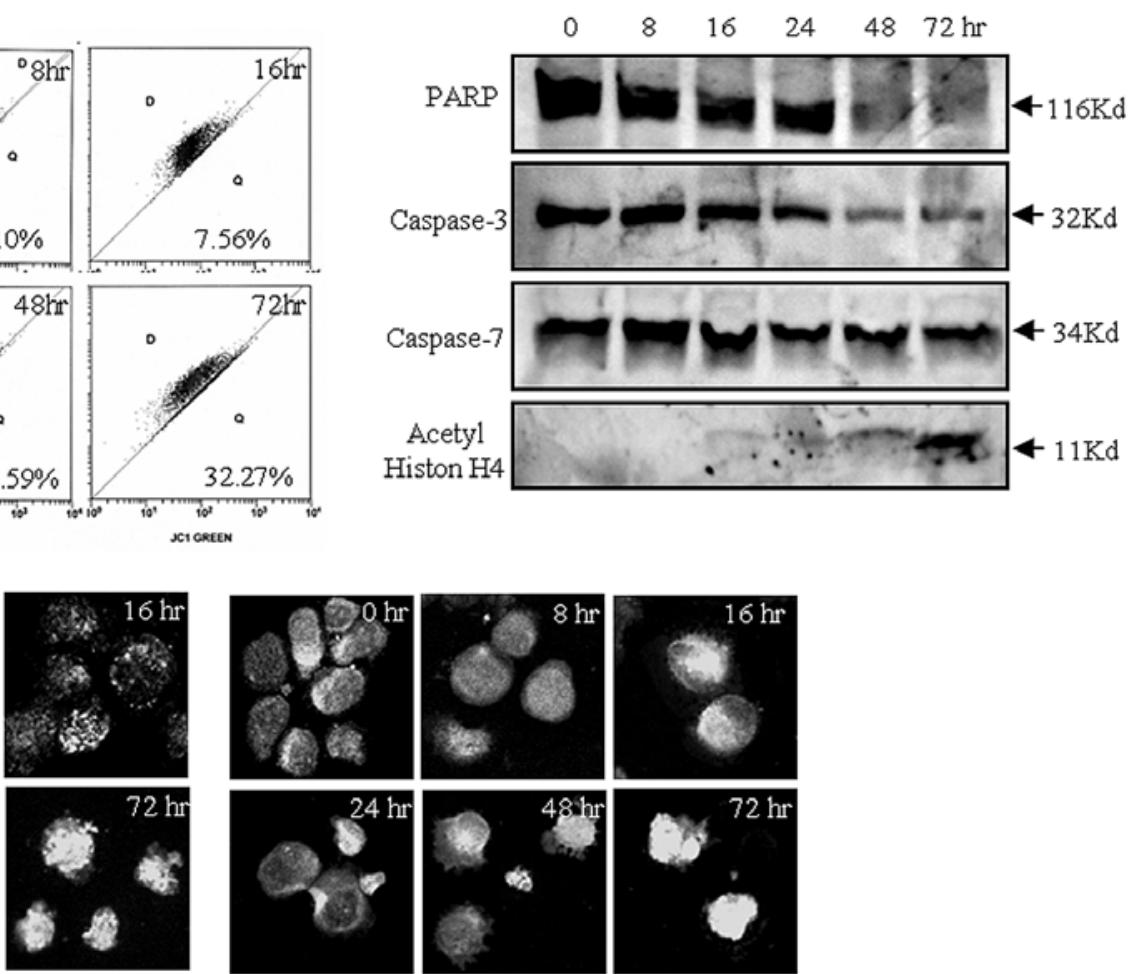

CAD

Figure 2. Involvement of mitochondria and caspase in VPA-induced apoptosis of KAT-18 cells. KAT-18 cells were incubated with 4.5 mM VPA for 0, 8 , 16, 24,48 , and $72 \mathrm{~h}$. (A) The loss of MMP $\left(\Delta \Psi_{\mathrm{m}}\right)$ of KAT-18 cells was significantly increased after VPA treatment. (B) Western blot analysis showed that VPA induced PARP, caspase-3, and caspase-7 degradation, and production of the acetyl histone H4 in a time-dependent manner. (C) Micrographs of immunofluorescence stained samples demonstrating VPA-mediation of translocation of AIF and CAD.

in some cells treated with VPA. However, typical nuclear condensation or fragmentation was not observed (Fig. 1B). Flow cytometry, which allowed the simultaneous estimation of cell cycle parameters and apoptosis, revealed decreased DNA content (Fig. 1C). However, ladder-like DNA fragments ranging in size from $\sim 200$ to 2,000 bp were not detected in DNA electrophoresis (Fig. 1D).

Involvement of mitochondria and caspases in VPA-induced apoptosis of KAT-18 cells. Loss of MMP $\left(\Delta \Psi_{\mathrm{m}}\right)$ is a common event in many pathways of apoptosis induction. To examine the mitochondrial involvement in this type of apoptosis, MMP assay was conducted. MMP decreased in VPA-treated cells (Fig. 2A). Time-dependent degradations of procaspase-3, procaspase-7, and PARP protein (p116 kDa) were also evident (Fig. 2B). We next examined whether AIF was translocated from mitochondria into the nucleus, since AIF causes peripheral chromatin condensation indicating stage I and high molecular weight DNA fragmentation. Translocation of both AIF and CAD from the cytoplasm into nucleus was evident in VPA-treated cells (Fig. 2C).

VPA reduces activity of histone deacetylase and induces histone hyperacetylation. A time-dependent increase of the amount of acetylated histone 4 was observed in VPA-treated cells (Fig. 2B). However, alterations in the levels of histone $2 \mathrm{~A}, 2 \mathrm{~B}$, and 3 were not evident (data not shown).
Co-treatment of $1 \mathrm{mMVPA}$ and $0.25 \mu \mathrm{M}$ doxorubicin efficiently induces apoptosis in KAT-18 cells. Whereas VPA at $1 \mathrm{mM}$ or doxorubicin at $0.25 \mu \mathrm{M}$ did not induce apoptosis in KAT-18 cells, co-treatment with $1 \mathrm{mM} \mathrm{VPA}$ and $0.25 \mu \mathrm{M}$ doxorubicin significantly decreased cell viability (Fig. 3A). Hoechst staining demonstrated condensation on peripheral chromatin in some cells treated with VPA plus doxorubicin. However, typical nuclear condensation or fragmentation was not observed (Fig. 3B). Flow cytometry revealed a decreased DNA content in cells treated with VPA plus doxorubicin (Fig. 3C). However, ladder-like DNA fragments ranging in size from 200 to 2,000 bp were not detected in DNA electrophoresis (Fig. 3D). MMP was reduced in cells co-treated with VPA and doxorubicin (Fig. 4A). Western blotting indicated that procaspase-3, procaspase-7, and PARP protein were degraded in co-treated cells (Fig. 4B). Confocal microscopy demonstrated that co-treatment of VPA and doxorubicin induced translocation of AIF and CAD into the nucleus (Fig. 4C).

Co-treatment of $1 \mathrm{mM} \mathrm{VPA}$ and $25 \mu \mathrm{M} \mathrm{HS}-1200$ efficiently induces apoptosis in KAT-18 cells. Whereas VPA at $1 \mathrm{mM}$ or HS-1200 at $25 \mu \mathrm{M}$ did not induce apoptosis in KAT-18 cells, co-treatment with $1 \mathrm{mM}$ VPA and $25 \mu \mathrm{M}$ HS-1200 significantly decreased cell viability (Fig. 5A). Hoechst staining showed condensation on peripheral chromatin in some cells treated with VPA plus HS-1200. However, typical 

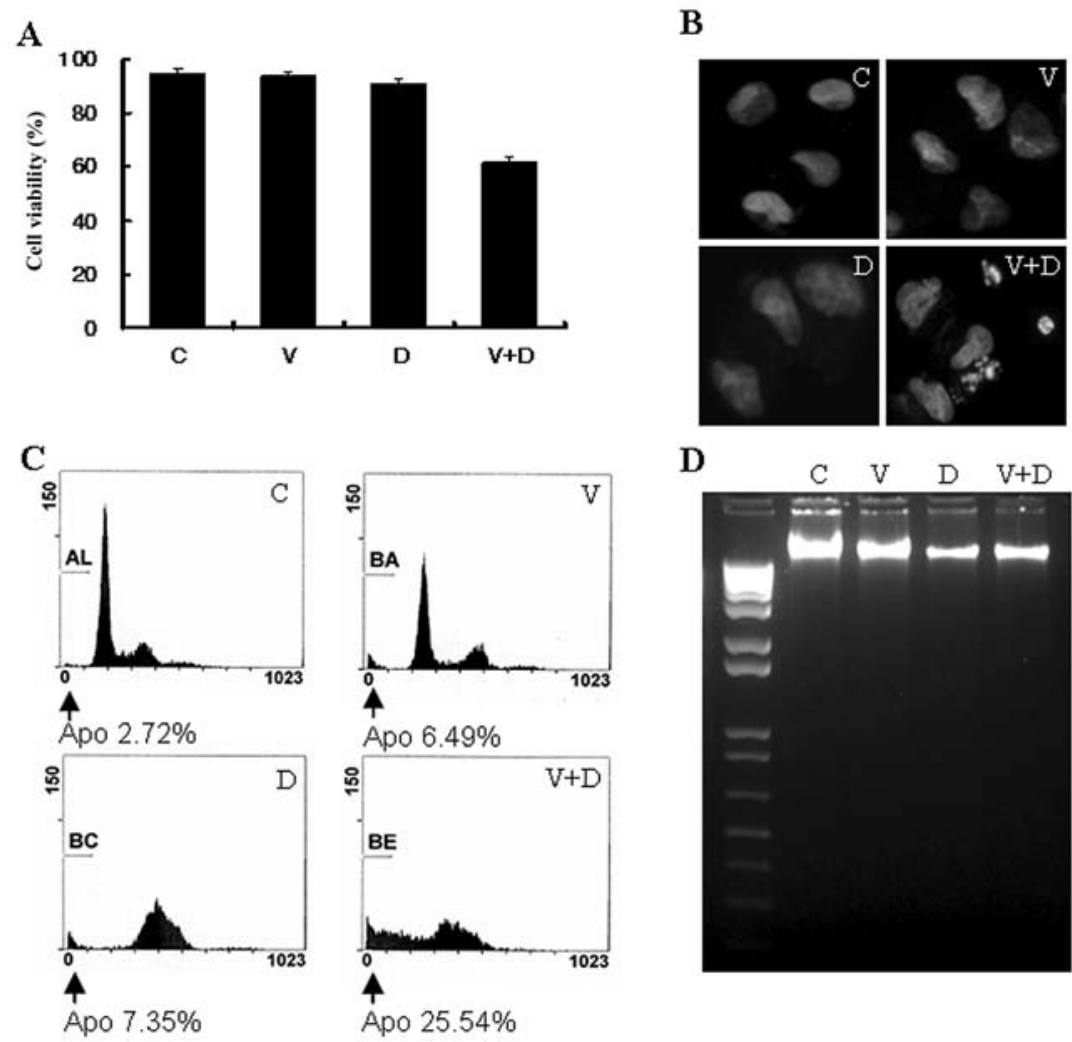

Figure 3. Co-treatment of $1 \mathrm{mM}$ VPA and $0.25 \mu \mathrm{M}$ doxorubicin efficiently induces apoptosis in KAT-18 cells. Treatments were: C, control cells; V, cells treated with $1 \mathrm{mM}$ VPA for $48 \mathrm{~h}$; D, cells treated with $0.25 \mu \mathrm{M}$ doxorubicin for $48 \mathrm{~h}$; V+D, cells treated with $1 \mathrm{mM}$ VPA plus $0.25 \mu \mathrm{M}$ doxorubicin for $48 \mathrm{~h}$. (A) Co-treatment of VPA and doxorubicin efficiently reduced cell viability in KAT-18 cells. Viability and data are as described in the legend to Fig. 1 . (B) Micrographs of Hoechst 33342 stained samples. Whereas typical nuclear condensation or fragmentation was not observed, cells showing peripheral chromatin condensations were observed in the V+D treatment. (C) Kinetic analysis of the effect of VPA and doxorubicin on KAT-18 cell cycle progression and induction of apoptosis. (D) DNA fragmentation analysis by agarose gel electrophoresis. Ladder-like DNA fragments were not observed.

A

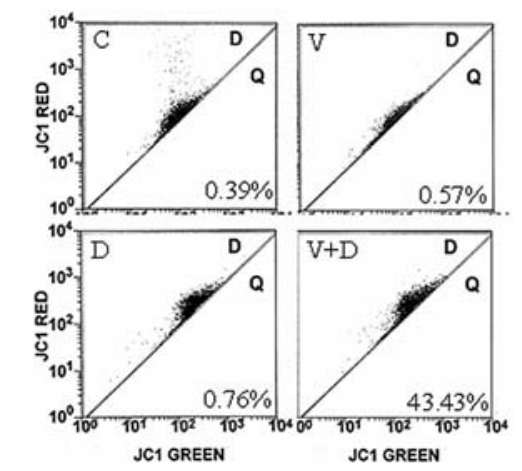

B

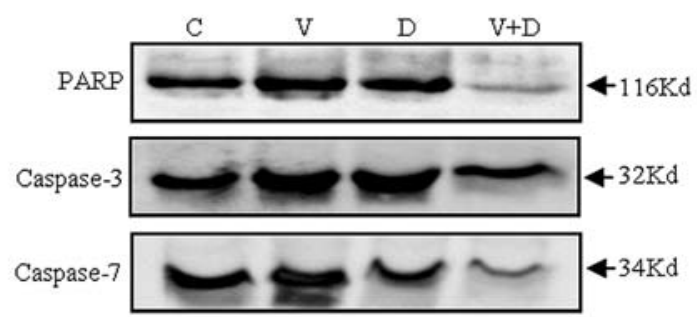

C

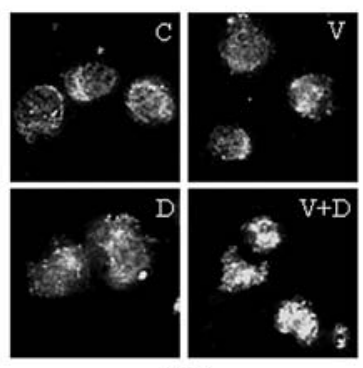

AIF
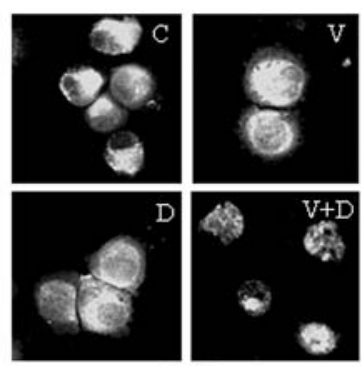

CAD

Figure 4. Co-treatment of $1 \mathrm{mM}$ VPA and $0.25 \mu \mathrm{M}$ doxorubicin efficiently induces apoptosis in KAT-18 cells via mitochondria and caspases. Treatments were: $\mathrm{C}$, control cells; V, cells treated with $1 \mathrm{mM}$ VPA for $48 \mathrm{~h}$; D, cells treated with $0.25 \mu \mathrm{M}$ doxorubicin for $48 \mathrm{~h}$; V+D, cells treated with $1 \mathrm{mM}$ VPA plus $0.25 \mu \mathrm{M}$ doxorubicin for $48 \mathrm{~h}$. (A) Loss of MMP $\left(\Delta \Psi_{\mathrm{m}}\right)$ was measured using JC-1 dye and with flow cytometry. (B) Western blot analysis showing that the V+D treatment induced PARP, procaspase-3, and procaspase-7 degradation. (C) Micrographs of immunofluorescence stained samples demonstrating translocation of $\mathrm{AIF}$ and $\mathrm{CAD}$ in $\mathrm{V}+\mathrm{D}$ treated cells. 
A

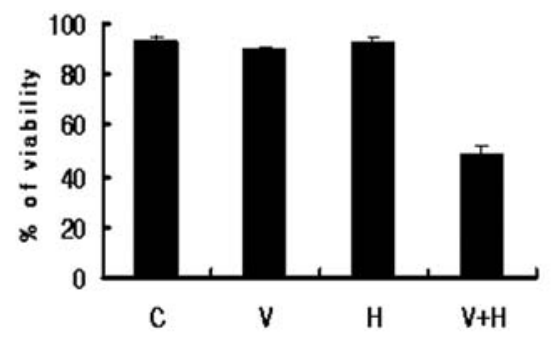

$\mathrm{C}$
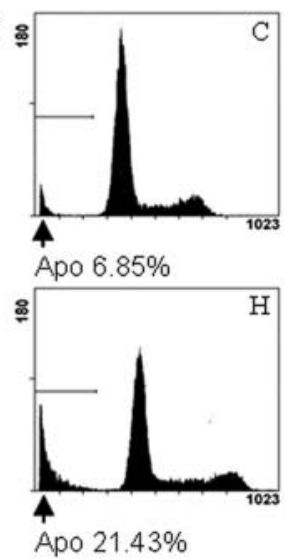

B

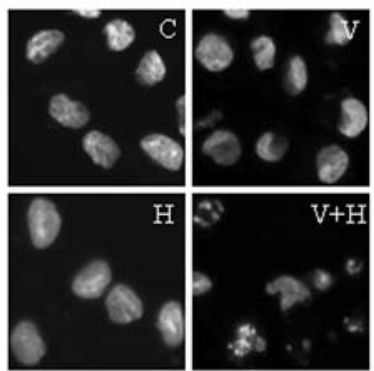

D

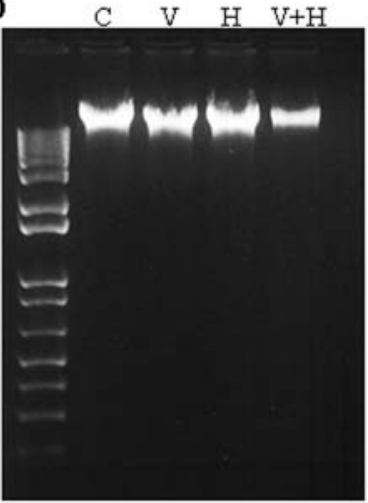

Figure 5. Co-treatment of $1 \mathrm{mM}$ VPA and $25 \mu \mathrm{M}$ HS-1200 efficiently induces apoptosis in KAT-18 cells. Treatments were: C, control cells; V, cells treated with $1 \mathrm{mM}$ VPA for $48 \mathrm{~h}$; H, cells treated with $25 \mu \mathrm{M}$ HS- 1200 for $48 \mathrm{~h}$; V+H, cells treated with $1 \mathrm{mM}$ VPA plus $25 \mu \mathrm{M}$ HS-1200 for $48 \mathrm{~h}$. (A) Co-treatment of VPA and HS-1200 efficiently reduced viability in KAT-18 cells. Viability and data are as described in the legend to Fig. 1. (B) Micrographs of Hoechst 33342 stained samples. Whereas typical nuclear condensation or fragmentation was not observed, cells showing peripheral chromatin condensations were observed in $\mathrm{V}+\mathrm{H}$ treated cells. (C) The kinetic analysis of the effect of $\mathrm{V}+\mathrm{H}$ treatment on KAT-18 cell cycle progression and induction of apoptosis. (D) DNA fragmentation analysis by the agarose gel electrophoresis. Ladder-like DNA fragments were not observed.

A
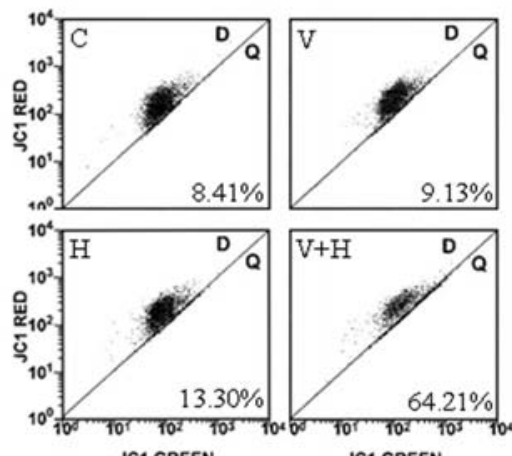

C
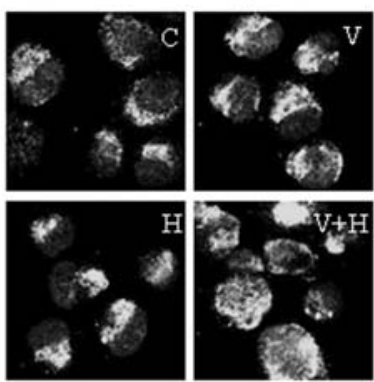

AIF
B
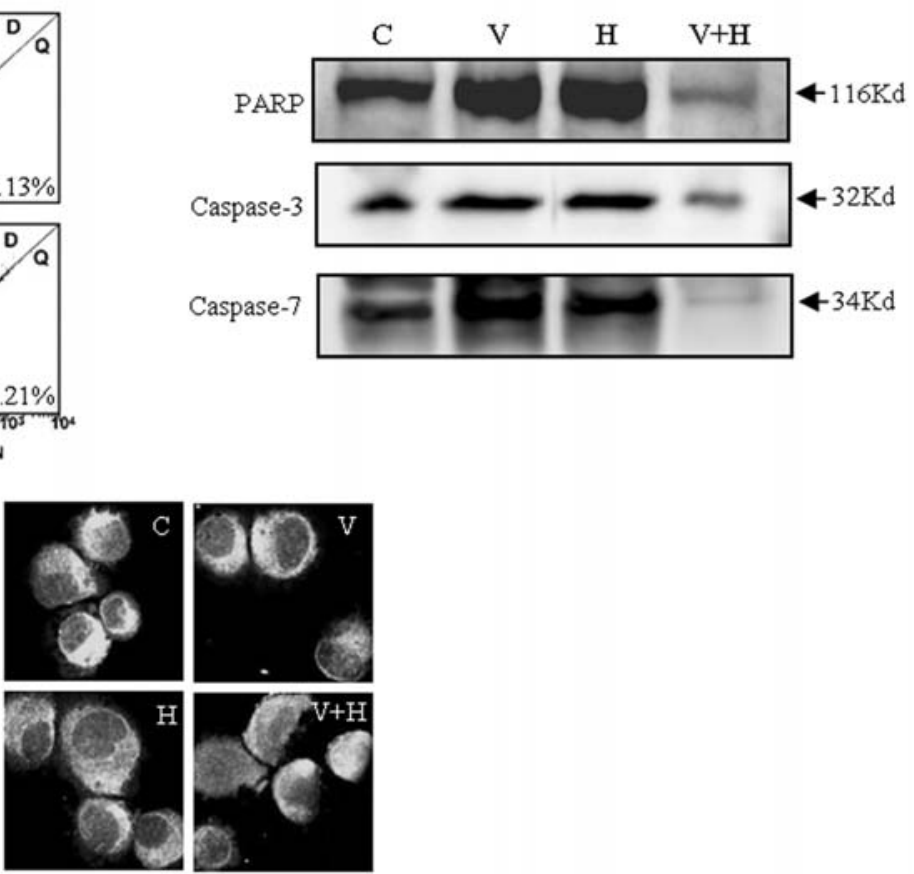

CAD

Figure 6. Co-treatment of $1 \mathrm{mM}$ VPA and $25 \mu \mathrm{M}$ HS-1200 efficiently induces apoptosis in KAT-18 cells via mitochondria and caspases. Treatments were: C, control cells; V, cells treated with $1 \mathrm{mM}$ VPA for $48 \mathrm{~h} ; \mathrm{H}$, cells treated with $25 \mu \mathrm{M}$ HS-1200 for $48 \mathrm{~h}$; V+H, cells treated with $1 \mathrm{mM}$ VPA plus $25 \mu \mathrm{M}$ HS-1200 for $48 \mathrm{~h}$. (A) Loss of MMP $\left(\Delta \Psi_{\mathrm{m}}\right)$ was measured using JC-1 dye and with flow cytometry. (B) Western blot analysis showed that $1 \mathrm{mM}$ VPA plus $25 \mu$ M HS-1200 induced PARP, procaspase-3, and procaspase-7 degradation. (C) Micrographs of immunofluorescence stained samples demonstrating translocation of AIF and CAD in $\mathrm{V}+\mathrm{H}$ treated cells. 
A
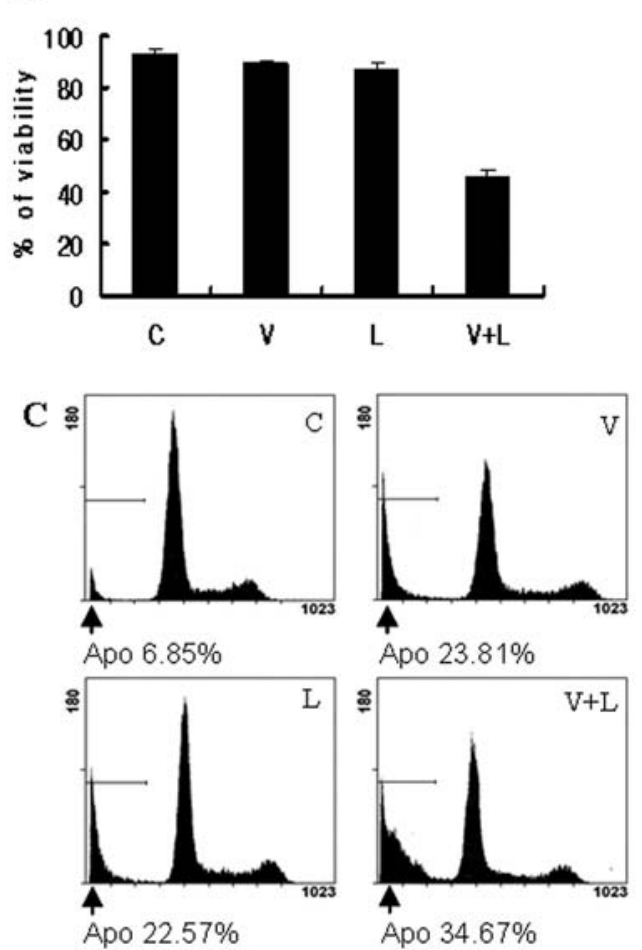

B

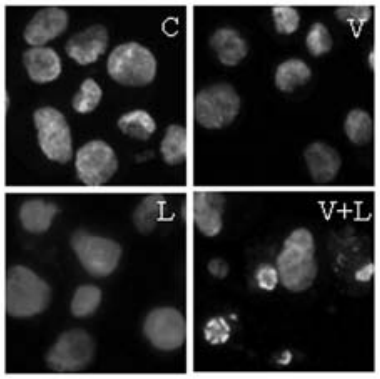

D

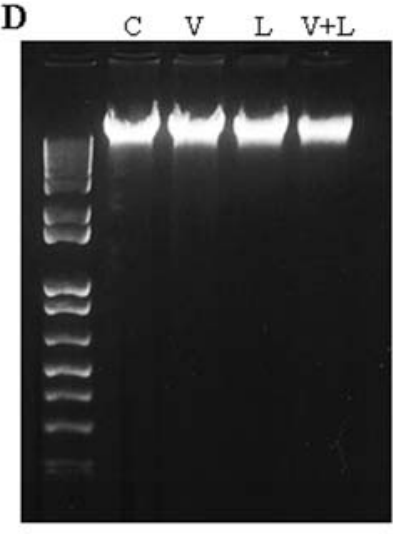

Figure 7. Co-treatment of $1 \mathrm{mM}$ VPA and $1 \mu \mathrm{M}$ lactacystin efficiently induces apoptosis in KAT-18 cells. Treatments were: C, control cells; V, cells treated with $1 \mathrm{mM}$ VPA for $48 \mathrm{~h}$; L, cells treated with $1 \mu \mathrm{M}$ lactacystin; V+L, cells treated with $1 \mathrm{mM}$ VPA plus $1 \mu \mathrm{M}$ lactacystin for $48 \mathrm{~h}$. (A) Co-treatment of VPA and lactacystin efficiently reduced viability in the KAT-18 cells. Viability and data are as described in the legend to Fig. 1. (B) Quantification of apoptosis based on nuclear morphology. KAT-18 cells were collected at each time-point and assessed for apoptosis by Hoechst 33342 staining. V+L treated cells showed condensation on peripheral chromatin. (C) Kinetic analysis of the effect of VPA and lactacystin on KAT-18 cell cycle progression and induction of apoptosis. (D) DNA fragmentation analysis by agarose gel electrophoresis. Ladder-like DNA fragments were not observed.

nuclear condensation or fragmentation was not observed (Fig. 5B). Flow cytometry demonstrated a decreased DNA content in co-treated cells (Fig. 5C). However, ladder-like DNA fragments were not detected in DNA electrophoresis (Fig. 5D). MMP was reduced in cells co-treated with VPA and doxorubicin (Fig. 6A). Western blotting showed the degradation of procaspase- 3 , procaspase-7, and PARP protein in co-treated cells (Fig. 6B). Confocal microscopy demonstrated that co-treatment of VPA and HS-1200 induced translocation of AIF and CAD into the nucleus (Fig. 6C).

Co-treatment of $1 \mathrm{mMVPA}$ and $1 \mu \mathrm{M}$ lactacystin efficiently induces apoptosis in KAT-18 cells. Whereas VPA at $1 \mathrm{mM}$ or lactacystin at $1 \mu \mathrm{M}$ did not induce apoptosis in KAT-18 cells, co-treatment with $1 \mathrm{mM} \mathrm{VPA}$ and $1 \mu \mathrm{M}$ lactacystin significantly decreased cell viability (Fig. 7A). Hoechst staining showed condensation on peripheral chromatin in some cells treated with VPA plus lactacystin. However, typical nuclear condensation or fragmentation was not observed (Fig. 7B). Flow cytometry demonstrated a decreased DNA content in co-treated cells (Fig. 7C). However, ladder-like DNA fragments were not detected in DNA electrophoresis (Fig. 7D). MMP was reduced in cells co-treated with VPA and lactacystin (Fig. 8A). Western blotting showed the degradations of procaspase-3, procaspase-7, and PARP protein in co-treated cells (Fig. 8B). Confocal microscopy demonstrated that co-treatment of VPA and lactacystin induced translocation of AIF and CAD into the nucleus (Fig. 8C).

\section{Discussion}

ATC is a relatively uncommon and highly aggressive neoplasm. Surgical excision is rarely feasible and ATC is the least radiosensitive among all thyroid tumors and is nonresponsive to I-131 therapy $(14,15)$. Chemotherapy is used if the tumor has characteristics of no response to I-131, nonoperability, and no effect to external radiotherapy.

Potentially better antitumor effectiveness at much lower drug doses and reduced extent and severity of treatmentrelated toxicity can be anticipated by combination treatment. HDACIs, which sensitize cancer cells to apoptosis, have also been employed for combination treatment. Synergistic antitumor efficacy exhibited by HDACIs and chemotherapeutic drugs has been demonstrated to result from multiple mechanisms such as up-regulation of proapoptotic proteins or downregulation of antiapoptotic members $(16,17)$. Despite current multimodal approaches to the treatment of ATC, prognosis is still grave. Therefore, a new therapeutic strategy for ATC is desperately needed.

Given that the antitumor activity of VPA is not accompanied by any signs of gross toxicity such as weight loss, diarrhea or gastrointestinal bleeding (18), a combination treatment utilizing VPA could potentially result in optimal antitumor effectiveness with much lower drug doses, thus reducing the extent and severity of treatment-related toxicity.

VPA has been used in the monotherapy or combination therapy for various types of malignancy $(11,19,20)$. In either 
A

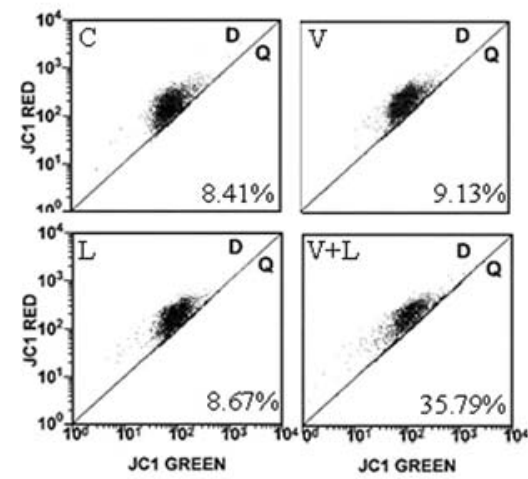

B

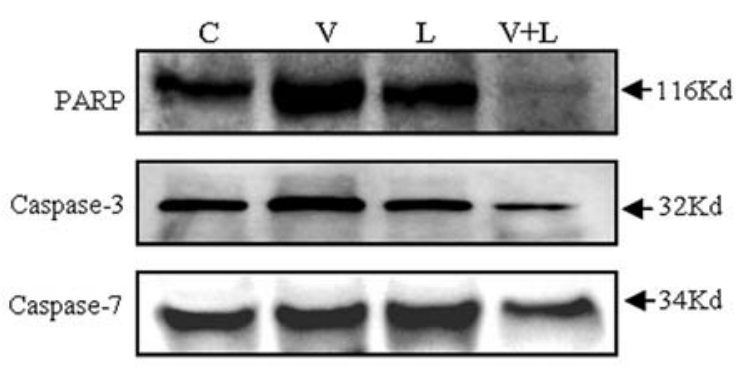

C
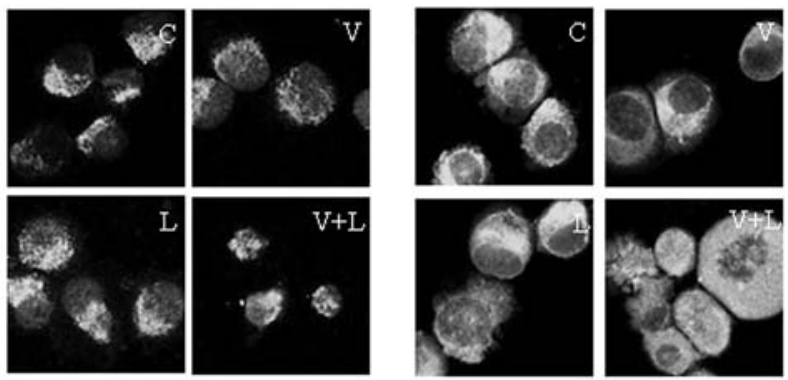

AIF

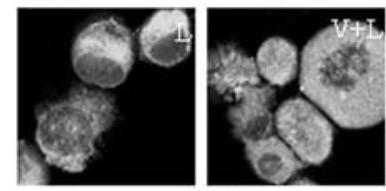

CAD

Figure 8. Co-treatment of $1 \mathrm{mM}$ VPA and $1 \mu \mathrm{M}$ lactacystin efficiently induces apoptosis in KAT-18 cells via mitochondria and caspases. Treatments were: $\mathrm{C}$, control cells; V, cells treated with $1 \mathrm{mM}$ VPA for $48 \mathrm{~h}$; L, cells treated $1 \mu \mathrm{M}$ lactacystin; V+L, cells treated with $1 \mathrm{mM}$ VPA plus $1 \mu \mathrm{M}$ lactacystin for $48 \mathrm{~h}$. (A) Loss of MMP $\left(\Delta \Psi_{\mathrm{m}}\right)$ significantly increased after VPA plus lactacystin treatment. (B) Western blot analysis showing that 1 mM VPA plus $1 \mu \mathrm{M}$ lactacystin induced PARP, procaspase-3, and procaspase-7 degradation. (C) Micrographs of immunofluorescence stained samples demonstrating translocation of AIF and CAD caused by VPA and lactacystin.

mode, VPA exhibits antiproliferative activity. Of note, VPA significantly enhances antipaeligerative activity at clinically relevant concentrations $(12,21)$ that can be achieved in a patient's serum when administering a daily dose of $20-30 \mathrm{mg} /$ $\mathrm{kg}$ for epilepsy. Thus, VPA represents a promising potential therapeutic agent for cancers. Presently, we demonstrate that VPA monotherapy is capable of inducing apoptosis.

Combination anticancer therapies using VPA and other drugs, especially compounds that are non-toxic, may offer a substantial advantage over VPA monotherapy in a clinical setting. VPA combined with all-trans retinoic acid (22) or interferon $\alpha$ (9) enhances the efficacy of each antitumor agent. Presently, three VPA-based combination anticancer therapies using doxorubicin, HT-1200, or lactacystin were explored for their efficacy against ATC. Doxorubicin is the most effective single agent against ATC. Although doxorubicin causes cell death, at least in part, by inducing apoptosis in ATC cells (23), the mechanism underlying its pharmacological efficacy is not been fully understood. HDACI sensitizes ATC cells to doxorubicin, which induces apoptosis by reducing histone deacetylase activity and inducing hyperacetylation of histone (24). These observations, combined with the knowledge that VPA augments doxorubicin efficacy, have made the combination of VPA and doxorubin an attractive speculative therapy. The present results bolster this approach by demonstrating the efficient induction of apoptosis in KAT-18 cells co-treated with VPA and doxorubicin.

Bile acids are polar derivatives of cholesterol that are essential for the absorption of dietary lipids, and which regulate the transcription of genes that control cholesterol homeostasis. Each kind of bile acid exhibits distinct biological effects (25). Natural bile salts inhibit cell proliferation and induce apoptosis in various cancer cells $(26,27)$. After synthesis by the liver and excretion into the bile canaliculus and the digestive tract, the primary bile acids cholic acid and CDCA are metabolized by enteric bacteria to produce secondary bile acids, primarily deoxycholic acid, ursodeoxycholic acid, and lithocholic acid. Conjugation of bile acids with glycine or taurine is one mechanism by which the hydrophobicity of bile acids is decreased $(28,29)$. Conjugation renders the molecules less cytotoxic at physiological concentrations (30). Elevated concentrations of bile acid within the liver induce hepatocyte apoptosis, which provides a cellular mechanism for bile acid-mediated liver injury (31). Additionally, the hydrophobic nature of bile acids correlates with induction of apoptosis and/or growth arrest (32).

Previous studies have demonstrated that several bile acid derivatives induce apoptosis in several human cancer cells including breast carcinoma cells, leukemic $\mathrm{T}$ cells, prostate cancer cells, and colon cancer cells (33-35). The synthetic CDCA derivative HS-1200 displays antitumor behavior when combined with lactacystin in p 815 mastocystoma cells (36). Furthermore, HS-1200 and another CDCA derivative, HS-1199, induce apoptosis of gastric cancer cells (37). It has been reported that several synthetic bile acids inhibit angiogenesis in human hepatocellular carcinoma cells (38) and that HS-1200 and HS-1199 are capable of inhibiting cell proliferation and inducing apoptosis in $\mathrm{SiHa}$ cells through 
activation of c-Jun N-terminal kinase and nuclear factor-B (NF-B) (39). The present data demonstrate that combination therapy with VPA and HT-1200 efficiently induces apoptosis in KAT-18 cells.

The proteasome is a fundamental non-lysosomal tool that cells use to process or degrade a variety of short-lived proteins. Proteolysis mediated by the ubiquitin-proteasome system has been implicated in the regulation of apoptosis (40). The proteasome pathway works upstream of mitochondrial alterations and caspase activation, and can be involved in different systems including NF-B, Bax, and Bcl-2 (41-43). Proteasome inhibitors, employed alone or combined with other anticancer agents, have been suggested as a new class of potential anticancer agents $(44,45)$. This increasing interest stems not only from their direct apoptosis-inducing activity but also from the possibility of the sensitization of neoplastic cells to other antitumor agents. In vitro data supports the idea that proteasome inhibitors increase the sensitivity of tumor cells to the apoptotic action of tumor necrosis factor (TNF), radiotherapy, or chemotherapy (46). One underlying apoptosis sensitization mechanism is the modulation of NF-B activation (47). On the other hand, proteasome inhibitors are capable of restoring retinoic acid sensitivity of acute promyelocytic leukemia cells through the inhibition of PML/RAR $\alpha$ degradation (48). One study has demonstrated that HS-1200 not only decreases proteasome activity, but that the co-treatment of the proteasome inhibitor lactacystin augments HS-1200-induced apoptosis (36). An in vivo investigation in mice that studied the effect of the combination treatment with a selective proteasome inhibitor and TNF in colon-26 adenocarcinoma also showed that the two drugs are extremely potent when administered together. The present data add to these findings by demonstrating that the combination of VPA with lactacystin efficiently induces apoptosis in KAT-18 cells.

In conclusion, while extensive clinical studies are still necessary combination therapy involving VPA with doxorubicin, HT-1200, or lactacystin holds potential as an alternative therapeutic strategy for ATC.

\section{Acknowledgements}

The KAT-18 cell line was kindly provided by Dr K.B. Ain, University of Kentucky Chandler Medical Center, Lexington, USA. This work was supported by Korea Research Foundation Grant (KRF-2006-J03501).

\section{References}

1. Strahl BD and Allis CD: The language of covalent histone modifications. Nature 403: 41-45, 2000.

2. Laherty CD, Yang WM, Sun JM, Davie JR, Seto E and Eisenman RN: Histone deacetylases associated with the $\mathrm{mSin} 3$ corepressor mediate mad transcriptional repression. Cell 89: 349-356, 1997

3. Verdin E, Dequiedt F and Kasler HG: Class II histone deacetylases: versatile regulators. Trends Genet 19: 286-293, 2003.

4. Yoshida M, Hoshikawa Y, Koseki K, Mori K and Beppu T: Structural specificity for biological activity of trichostatin A, a specific inhibitor of mammalian cell cycle with potent differentiation-inducing activity in Friend leukemia cells. J Antibiot 43: 1101-1106, 1990.

5. Marks PA, Richon VM and Rifkind RA: Histone deacetylase inhibitors: inducers of differentiation or apoptosis of transformed cells. J Natl Cancer Inst 92: 1210-1216, 2000.
6. De Ruijter AJ, van Gennip AH, Caron HN, Kemp S and van Kuilenburg AB: Histone deacetylases (HDACs): characterization of the classical HDAC family. Biochem J 370: 737-749, 2003.

7. Cinatl J Jr, Cinatl J, Dsiever PH, et al: Sodium valproate inhibits in vivo growth of human neuroblastoma cells. Anticancer Drugs 8: 958-963, 1997.

8. Kramer OH, Zhu P, Ostendorff HP, et al: The histone deacetylase inhibitor valproic acid selectively induces proteasomal degradation of HDAC2. EMBO J 22: 3411-3420, 2003.

9. Cinatl J Jr, Kotchetkov R, Blaheta R, Driever PH, Vogel JU and Cinatl $\mathrm{J}$ : Induction of differentiation and suppression of malignant phenotype of human neuroblastoma BE(2)-C cells by valproic acid: enhancement by combination with interferonalpha. Int J Oncol 20: 97-106, 2002.

10. Gurvich N, Tsygankova OM, Meinkoth JL and Klein PS: Histone deacetylase is a target of valproic acid-mediated cellular differentiation. Cancer Res 64: 1079-1086, 2004.

11. Li XN, Shu Q, Su JM, Perlaky L, Blaney SM and Lau CC: Valproic acid induces growth arrest, apoptosis, and senescence in medulloblastomas by increasing histone hyperacetylation and regulating expression of $\mathrm{p} 21^{\mathrm{Cip} 1}, \mathrm{CDK} 4$, and CMYC. Mol Cancer Ther 4: 1912-1922, 2005.

12. Takai N, Desmond JC, Kumagai T, et al: Histone deacetylase inhibitors have a profound antigrowth activity in endometrial cancer cells. Clin Cancer Res 10: 1141-1149, 2004.

13. Im EO, Choi YH, Paik KJ, et al: Novel bile acid derivatives induce apoptosis via a p53-independent pathway in human breast carcinoma cells. Cancer Lett 163: 83-93, 2001

14. Pierie JP, Muzikansky A, Gaz RD, Faquin WC and Ott MJ: The effect of surgery and radiotherapy on outcome of anaplastic thyroid carcinoma. Ann Surg Oncol 9: 57-64, 2002.

15. Levendag PC, De Porre PM and van Putten WL: Anaplastic carcinoma of the thyroid gland treated by radiation therapy. Int $\mathrm{J}$ Radiat Oncol Biol Phys 26: 125-128, 1993.

16. Roh MS, Kim CW, Park BS, et al: Trichostatin A induces apoptosis on human osteosarcoma cells in histone acetylationand mitochondria-dependent fashions. Apoptosis 9: 583-589, 2004.

17. Zhang XD, Gillespie SK, Borrow JM and Hersey P: The histone deacetylase inhibitor suberic bishydroxamate: a potential sensitizer of melanoma to TNF-related apoptosis-inducing ligand (TRAIL) induced apoptosis. Biochem Pharmacol 66: 1537-1545, 2003.

18. Golab J, Stoklosa T, Czajka A, et al: Synergistic antitumor effects of a selective proteasome inhibitor and TNF in mice. Anticancer Res 20: 1717-1721, 2000.

19. Kieslich M, Schwabe D, Cinatl J Jr and Driever PH: Increase of fetal hemoglobin synthesis indicating differentiation induction in children receiving valproic acid. Pediatr Hematol Oncol 20: 15-22, 2003.

20. Warrell RP Jr, He LZ, Richon V, Calleja E and Pandolfi PP: Therapeutic targeting of transcription in acute promyelocytic leukemia by use of an inhibitor of histone deacetylase. J Natl Cancer Inst 90: 1621-1625, 1998.

21. Graziani G, Tentori L, Portarena I, Vergati M and Navarra P: Valproic acid increases the stimulatory effect of estrogens on proliferation of human endometrial adenocarcinoma cells. Endocrinology 144: 2822-2828, 2003.

22. Mongan NP and Gudas LJ: Valproic acid, in combination with all-trans retinoic acid and 5-aza-2'-deoxycytidine, restores expression of silenced RARbeta 2 in breast cancer cells. Mol Cancer Ther 4: 477-486, 2005.

23. Massart C, Barbet R, Genetet N and Gibassier J: Doxorubicin induces Fas-mediated apoptosis in human thyroid carcinoma cells. Thyroid 14: 263-270, 2004.

24. Rho JH, Kang DY, Park KJ, et al: Doxorubicin induces apoptosis with profile of large-scale DNA fragmentation and without DNA ladder in anaplastic thyroid carcinoma cells via histone hyperacetylation. Int J Oncol 27: 465-471, 2005.

25. Hofmann AF: Chemistry and enterohepatic circulation of bile acids. Hepatology 4: 4-14, 1984.

26. Martinez JD, Stratagoules ED, LaRue JM, et al: Different bile acids exhibit distinct biological effects: the tumor promoter deoxycholic acid induces apoptosis and the chemopreventive agent ursodeoxycholic acid inhibits cell proliferation. Nutr Cancer 31: 111-118, 1998.

27. Jones B, Roberts PJ, Faubion WA, Kominami E and Gores GJ: Cystatin A expression reduces bile salt-induced apoptosis in a rat hepatoma cell line. Am J Physiol 275: 723-730, 1998. 
28. Martinez-Diez MC, Serrano MA, Monte MJ and Marin JJ: Comparison of the effects of bile acids on cell viability and DNA synthesis by rat hepatocytes in primary culture. Biochim Biophys Acta 1500: 153-160, 2000.

29. Rust C, Karnitz LM, Paya CV, Moscat J, Simari RD and Gores GJ: The bile acid taurochenodeoxycholate activates a phosphatidylinositol 3-kinase-dependent survival signaling cascade. J Biol Chem 275: 20210-20216, 2000.

30. Patel T, Bronk SF and Gores GJ: Increases of intracellular magnesium promote glycodeoxycholate-induced apoptosis in rat hepatocytes. J Clin Invest 94: 2183-2192, 1994.

31. Patel T, Roberts LR, Jones BA and Gores GJ: Dysregulation of apoptosis as a mechanism of liver disease: an overview. Semin Liver Dis 18: 105-114, 1998.

32. Powell AA, LaRue JM, Batta AK and Martinez JD: Bile acid hydrophobicity is correlated with induction of apoptosis and/or growth arrest in HCT116 cells. Biochem J 356: 481-486, 2001

33. Kim ND, Im EO, Choi YH and Yoo YH: Synthetic bile acids: novel mediators of apoptosis. J Biochem Mol Biol 35: 134-141, 2002.

34. Choi YH, Im EO, Suh H, Jin Y, Yoo YH and Kim ND Apoptosis and modulation of cell cycle control by synthetic derivatives of ursodeoxycholic acid and chenodeoxycholic acid in human prostate cancer cells. Cancer Lett 199: 157-167, 2003.

35. Park SE, Choi HJ, Yee SB, et al: Synthetic bile acid derivatives inhibit cell proliferation and induce apoptosis in HT-29 human colon cancer cells. Int J Oncol 25: 231-236, 2004.

36. Seo SY, Jun EJ, Jung SM, et al: Synthetic chenodeoxycholic acid derivative HS-1200-induced apoptosis of p815 mastocytoma cells is augmented by co-treatment with lactacystin. Anticancer Drugs 14: 219-225, 2003.

37. Jeong JH, Park JS, Moon B, et al: Orphan nuclear receptor Nur77 translocates to mitochondria in the early phase of apoptosis induced by synthetic chenodeoxycholic acid derivatives in human stomach cancer cell line SNU-1. Ann NY Acad Sci 1010: 171-177, 2003.

38. Suh H, Jung EJ, Kim TH, Lee HY, Park YH and Kim KW: Anti-angiogenic activity of ursodeoxycholic acid and its derivatives. Cancer Lett 113: 117-122, 1997.
39. Im E, Choi SH, Suh H, Choi YH, Yoo YH and Kim ND: Synthetic bile acid derivatives induce apoptosis through a c-Jun $\mathrm{N}$-terminal kinase and NF kappaB-dependent process in human cervical carcinoma cells. Cancer Lett 229: 49-57, 2005.

40. Drexler HC, Risau W and Konerding MA: Inhibition of proteasome function induces programmed cell death in proliferating endothelial cells. FASEB J 14: 65-77, 2000.

41. Orlowski RZ: The role of the ubiquitin-proteasome pathway in apoptosis. Cell Death Differ 6: 303-313, 1999.

42. Grimm LM, Goldberg AL, Poirier GG, Schwartz LM and Osborne BA: Proteasomes play an essential role in thymocyte apoptosis. EMBO J 15: 3835-3844, 1996.

43. Li B and Dou QP: Bax degradation by the ubiquitin/proteasomedependent pathway: involvement in tumor survival and progression. Proc Natl Acad Sci USA 97: 3850-3855, 2000.

44. Orlowski RZ, Eswara JR, Lafond-Walker A, Grever MR, Orlowski $\mathrm{M}$ and Dang CV: Tumor growth inhibition induced in a murine model of human Burkitt's lymphoma by a proteasome inhibitor. Cancer Res 58: 4342-4348, 1998.

45. Adams J, Palombella VJ, Sausville EA, et al: Proteasome inhibitors: a novel class of potent and effective antitumor agents. Cancer Res 59: 2615-2622, 1999.

46. Chandra J, Niemer I, Gilbreath J, et al: Proteasome inhibitors induce apoptosis in glucocorticoid-resistant chronic lymphocytic leukemic lymphocytes. Blood 92: 4220-4229, 1998.

47. Delic J, Masdehors P, Omura S, et al: The proteasome inhibitor lactacystin induces apoptosis and sensitizes chemo- and radioresistant human chronic lymphocytic leukaemia lymphocytes to TNF-alpha-initiated apoptosis. Br J Cancer 77: 1103-1107, 1998.

48. Fanelli M, Minucci S, Gelmetti V, Nervi C, GambacortiPasserini C and Pelicci PG: Constitutive degradation of PML/ RARalpha through the proteasome pathway mediates retinoic acid resistance. Blood 93: 1477-1481, 1999. 